\title{
The levels and distribution of organochlorine pesticides (OCPs) in sediments from the Haihe River, China
}

\author{
Rui-qiang Yang ${ }^{a}$, Ai-hua Lv ${ }^{\mathrm{b}}$, Jian-bo Shi ${ }^{\mathrm{a}}$, Gui-bin Jiang ${ }^{\mathrm{a}, *}$ \\ ${ }^{a}$ Key Laboratory of Environmental Chemistry and Ecotoxicology, Research Center for Eco-Environmental Sciences, \\ Chinese Academy of Sciences, P.O. Box 2871, Beijing 100085, China \\ b Urumq Environmental Monitoring Station, Beiyi Park Road 8, Urumq 830000, China
}

Received 22 October 2004; received in revised form 2 February 2005; accepted 24 February 2005

Available online 19 April 2005

\begin{abstract}
The levels and distribution patterns of the selected organochlorine pesticides (OCPs $=p, p^{\prime}$-DDT, $o, p^{\prime}$-DDT, $p, p^{\prime}$ DDE, $p, p^{\prime}$-DDD, $\alpha-, \beta-, \gamma-$ and $\delta$-HCH) in surficial sediments from the Haihe River and Dagu Drainage River of Tianjin were investigated by means of gas chromatography coupled with micro-electronic capture detector (GC- $\mu \mathrm{ECD})$. Concentrations of OCPs in the sediments from the Haihe River ranged from 1.88 to $18.76 \mathrm{ngg}^{-1}$ (mean $7.33 \mathrm{ngg}^{-1}$ ) for $\sum \mathrm{HCH}, 0.32-80.18 \mathrm{ngg}^{-1}$ (mean $15.94 \mathrm{ng} \mathrm{g}^{-1}$ ) for $\sum D D T$. Compared with the Haihe River, the Dagu Drainage River was much more contaminated by HCHs and DDTs, wherein $\sum \mathrm{HCH}$ ranged from 33.24 to $141.03 \mathrm{ng} \mathrm{g}^{-1}$ (mean $87.74 \mathrm{ngg}^{-1}$ ) and $\sum$ DDT ranged from 3.60 to $83.49 \mathrm{ngg}^{-1}$ with a mean value of $35.52 \mathrm{ng} \mathrm{g}^{-1}$. The concentration distribution of $\sum D D T$ and $\sum H C H$ was different indicated their different contamination sources. Composition analyses indicated that a recent usage or discharge of $\mathrm{HCH}$ and DDT into the Dagu Drainage River.
\end{abstract}

(c) 2005 Elsevier Ltd. All rights reserved.

Keywords: Aquatic environment; DDT; HCH; POPs; Pollution

\section{Introduction}

Organochlorine pesticides (OCPs) have been of great concern because of the large production and usage, their deleterious effect on non-target organism, ubiquity, bioaccumulation and persistence in the environment (Willett et al., 1998). Technical HCH and DDT were the most extensively used pesticides in China, resulting in widespread contamination in various environmental compartments (Wu et al., 1999; Zhou et al., 2001). These

\footnotetext{
* Corresponding author. Tel.: +86 10 62849334; fax: +86 10 62849179.

E-mail address: gbjiang@mail.rcees.ac.cn (G.-b. Jiang).
}

chemicals can enter aquatic environment through several ways such as effluents release, agricultural runoff, atmospheric deposition and other means. Due to the low water solubility, OCPs have a strong affinity for suspended particulates and subsequently settle down to sediments. One of the major sinks is thought to be the river and marine sediments (Doong et al., 2002). Therefore, the investigation of OCPs in sediments can provide a valuable record of contamination in aquatic environment.

Tianjin is one of the most severely contaminated areas by $\mathrm{HCHs}$ and DDTs in China because of its long-term usage and wastewater discharge from local industries. Although the production of $\mathrm{HCH}$ and DDT was officially banned in China since 1983, the 
actual application lasted for four decades from 1953 to 1993 in Tianjin. In addition, the production of technical $\mathrm{HCH}$ and lindane (pure $\gamma-\mathrm{HCH}$ ) was not stopped until 2000, while the DDT production may continue. Recent studies indicated that the levels of OCPs in agricultural soil of Tianjin region remained high (Gong et al., 2004).

The Haihe River, the largest water system in north China, flows through Tianjin city and empties into the Bohai Sea. With the rapid economic growth, industrialization, and urbanization, accompanied by inadequate infrastructure investment and management capacity, water shortage and water pollution are becoming extremely concernful. Water shortage has become a bottleneck to the further development of the economy and crop production. Serious pollution and environmental degradation have aggravated the water scarcity by reducing the availability of usable fresh water. The Dagu Drainage River is a very important channel to discharge various wastewater from domestic and industries in Tianjin and finally empties into the Bohai Sea. However, to our knowledge, few data are available for the contamination of OCPs in these rivers. This paper presents the levels and distributions of OCPs in the surficial sediments from the Haihe River and the Dagu Drainage River and their contamination profiles and possible sources of OCPs were also discussed.

\section{Materials and methods}

\subsection{Sample collection}

A total of 40 sediment samples in 13 sites along the Haihe River and Dagu Drainage River were collected during four sampling campaigns on April 8-9 (H1), July 12-13 (H2), September 6-7 (H3) and November 15-16 (H4), 2003, respectively. Fig. 1 shows the study area and the sampling locations. The sediments of S1 and S2 were collected from Beiyun River and Ziya River, which converged into the Haihe River before flowing through Tianjin city. S3, lies in urban districts, is an important crossing point of several branches of the Haihe River. S4 is the locus where Haihe River flowing out from Tianjin city. S6 and S9 are located at the two brakes of the Haihe River. S10 is the estuary of the Haihe River. S7 is the location just before the Machangjian River inpouring into the Haihe River, while sediments S8 were collected from the Machangjian River. Dagu Drainage River is an important drainage river in Tianjin city and samples of S11, S12 and S13 were collected.

The surficial sediments (top $0-3 \mathrm{~cm}$ ) were collected with a stainless steel grab and then placed into polytetrafluoroethylene (PTFE) bags. All the samples were immediately transferred to the laboratory and kept at $-20{ }^{\circ} \mathrm{C}$ in the refrigerator. The samples were freezedried, homogenized and passed through a $63-\mu \mathrm{m}$ sieve. All the equipments used for sample collection, transportation, and preparation, were free from organochlorines contamination.

\subsection{Instrumental}

Quantitative analyses of OCPs in sediments were accomplished by an Agilent $6890 \mathrm{~A}$ gas chromatography (GC) equipped with a ${ }^{63} \mathrm{Ni}$ electron capture detector ( $\mu$ ECD). A HP-1 fused silica capillary column $(50 \mathrm{~m}$ length $\times 0.32 \mathrm{~mm}$ i.d. $\times 0.25 \mu \mathrm{m}$ film thickness) was used

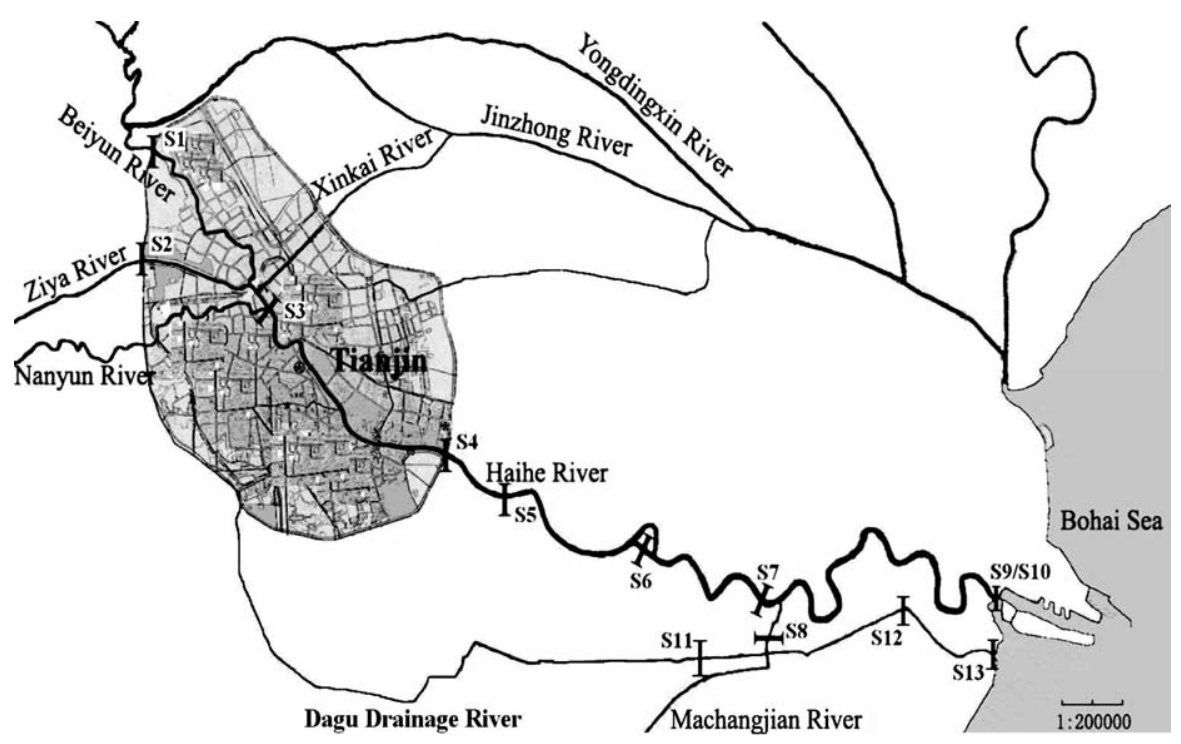

Fig. 1. Map of the study area and sampling sites. 
for separating the OCPs. One microliter of each sample was injected in a splitless model. Oven temperature increased from $80^{\circ} \mathrm{C}$ (held for $1 \mathrm{~min}$ ) to $180^{\circ} \mathrm{C}$ (held for $2 \mathrm{~min}$ ) at the rate of $50^{\circ} \mathrm{C} / \mathrm{min}$, followed to $230^{\circ} \mathrm{C}$ (held for $2 \mathrm{~min}$ ) at the rate of $5^{\circ} \mathrm{C}$, and then programmed to $270{ }^{\circ} \mathrm{C}$ at $10^{\circ} \mathrm{C} / \mathrm{min}$, held for $15 \mathrm{~min}$. The temperatures of injector and detector were $220^{\circ} \mathrm{C}$ and $300^{\circ} \mathrm{C}$, respectively. High pure nitrogen was used as both the carrier gas and make-up gas with a flow rate of 1.0 and $59 \mathrm{ml} / \mathrm{min}$, respectively. Peak identification was conducted by the accurate retention time of each standard $( \pm 1 \%)$ and also confirmed by GC-MS.

\subsection{Standards and reagents}

The standard solution of composite OCPs including $\alpha-, \beta-, \gamma-, \delta$-HCH and $p, p^{\prime}$-DDT, $o, p^{\prime}$-DDT, $p, p^{\prime}$-DDE, $p, p^{\prime}$-DDD was purchased from National Research Center for Certified Reference Materials of China. In the meanwhile, the corresponding individual standard of OCPs was also prepared for qualitative purpose. The internal standard 2,2', 3,3' 4,4' 5,5' 6,6'-decachlorobiphenyl was purchased from Accustandard, Inc. USA. Florisil (100-200 mesh, Beijing Yizhong Chemical Regents Factory, China) was activated in the oven at $160{ }^{\circ} \mathrm{C}$ for $8 \mathrm{~h}$. The organic reagents including hexane, dichloromethane were redistilled before use.

\subsection{Analytical procedure}

Total organic carbon contents were determined using Apollo 9000 TOC analyzer (Tekmar-Dohrmann Co., USA). The analytical procedure of OCPs residues in sediments was a modification of the method described by Yang et al. (2004). Briefly, $5 \mathrm{~g}$ of freeze-dried sample was weighed and a suitable amount of internal standard was added then extracted for $40 \mathrm{~min}$ with sonication method using $60 \mathrm{ml}$ of hexane-dichloromethane (1:1 $\mathrm{v} / \mathrm{v}$ ), stood overnight (about $10 \mathrm{~h}$ ) and was again sonicated for $20 \mathrm{~min}$. The extract was decanted, another $10 \mathrm{ml}$ of hexane was used to extract for $20 \mathrm{~min}$. The two extracts were combined and the activated $\mathrm{Cu}$ was added to remove element sulfate. The extracts were concentrated to about $1-2 \mathrm{ml}$ by a rotary evaporator, and further purified with a glass column (12 mm i.d.) loaded with $10 \mathrm{~g}$ of activated Florisil. The elution was subsequently carried out using $10 \mathrm{ml}$ of hexane, followed by $30 \mathrm{ml}$ of hexane containing $25 \%$ dichloromethane (v/v). The effluents were concentrated to a final volume of $0.5 \mathrm{ml}$ for $\mathrm{GC}$ analysis.

The residue levels of OCPs were quantitatively determined by the internal standard method using peak area. The correlation coefficients $(r)$ of calibration curves of HCHs and DDTs were all higher than 0.998. The detection limits (LODs) of the method were described as three times signal versus noise value $(\mathrm{S} / \mathrm{N})$. For every set of eight samples, a procedural blank and a spiked sample with standards were run to check for the interference and cross-contamination. The LODs ranged from $0.04 \mathrm{ngg}^{-1} \mathrm{dw}$ for $\delta$-HCH and $p, p^{\prime}$-DDE to 0.19 $\mathrm{ngg}^{-1} \mathrm{dw}$ for $\alpha-\mathrm{HCH}$. The spiked recoveries of OCPs using $10 \mathrm{ng}$ of composite standards were in the range of $87-103 \%$ and the relative standard deviation (RSD) values ranged from $2 \%$ to $14 \%$.

\section{Results and discussion}

\subsection{Contamination status of OCPS}

The contents of total organic carbon (TOC) and the concentrations of $\mathrm{HCHs}(\alpha-, \beta-, \gamma-$, and $\delta-\mathrm{HCH})$ and DDTs ( $p, p^{\prime}$-DDT, $o, p^{\prime}$-DDT, $p, p^{\prime}$-DDE, $p, p^{\prime}$-DDD) of the samples were all shown in Table 1 . The detection rates of both of $\sum \mathrm{HCH}$ and $\sum \mathrm{DDT}$ in the sediments are up to $100 \%$, which indicates wide occurrence of these compounds in the Haihe River and Dagu Drainage River. Significant differences of $\sum \mathrm{HCH}$ and $\sum \mathrm{DDT}$ in four batches of samples $(\mathrm{H} 1, \mathrm{H} 2, \mathrm{H} 3$ and $\mathrm{H} 4)$ were tested using One-way ANOVA method. The results showed that there were no significant differences among these four batches of samples $(P=0.05)$. The status of OCPs contamination in sediments in this study was compared with those in other riverine and coastal regions (Table 2). Concentrations of OCPs in the sediments from the Haihe River ranged from 1.88 to $18.76 \mathrm{ngg}^{-1}$ (mean $7.33 \mathrm{ngg}^{-1}$ ) for $\sum \mathrm{HCH}, 0.32$ $80.18 \mathrm{ngg}^{-1}$ (mean $15.94 \mathrm{ngg}^{-1}$ ) for $\sum D D T$. Amongst the Chinese large rivers, the levels of $\sum \mathrm{HCH}$ and $\sum$ DDT in sediments from Haihe River ranked the highest, with which only the residue levels in sediments from Mingjiang can be comparable (Hu et al., 1996; Wu et al., 1999; Zhang et al., 1996; Hong et al., 1999; Doong et al., 2002). When compared with other regions over the world, mean concentration of $\mathrm{SHCH}$ in the sediments of Haihe River is less than those of the Parramata River, Australia and the Mataniko River, Solomon but higher than others. For the concentrations of $\sum D D T$, some regions such as Indian Mandovi River Estuary, Australian Parramata River, Soloman Mataniko River showed the relatively higher concentrations (Iwata et al., 1994; Lee et al., 2001). However, compared with the Haihe River, the Dagu Drainage River was much more contaminated by $\mathrm{HCH}$ and DDTs, wherein $\sum \mathrm{HCH}$ ranged from 33.24 to $141.03 \mathrm{ngg}^{-1}$ (mean $87.74 \mathrm{ng} \mathrm{g}^{-1}$ ), while $\sum$ DDT ranged from 3.60 to $83.49 \mathrm{ngg}^{-1}$ with a mean value of $35.52 \mathrm{ng} \mathrm{g}^{-1}$.

\subsection{Spatial distribution of OCPS}

The kinetic behavior of hydrophobic organic pollutants is much influenced by organic carbon contents in 
Table 1

Concentrations of OCPs $\left(\mathrm{ngg}^{-1} \mathrm{dw}\right)$ and the TOC contents in the sediments from the Haihe River and Dagu Drainage River

\begin{tabular}{|c|c|c|c|c|c|c|c|c|c|c|c|}
\hline Sampling & $\begin{array}{l}\text { TOC } \\
\left(\mathrm{mg} \mathrm{g}^{-1}\right)\end{array}$ & $\alpha-\mathrm{HCH}$ & $\beta-\mathrm{HCH}$ & $\gamma-\mathrm{HCH}$ & $\delta-\mathrm{HCH}$ & $\sum \mathrm{HCH}$ & $p, p^{\prime}-\mathrm{DDE}$ & $p, p^{\prime}-\mathrm{DDD}$ & $o, p^{\prime}-\mathrm{DDT}$ & $p, p^{\prime}$-DDT & $\sum \mathrm{DDT}$ \\
\hline \multicolumn{12}{|c|}{ April 8-9 (H1) } \\
\hline $\mathrm{S} 1$ & 9.95 & 2.88 & 1.77 & 0.30 & 1.00 & 5.95 & 5.56 & 1.66 & 0.31 & 1.41 & 8.94 \\
\hline $\mathrm{S} 2$ & 12.08 & 1.02 & 0.88 & $<0.05$ & 0.31 & 2.21 & 0.19 & 0.15 & $<0.09$ & 0.14 & 0.48 \\
\hline $\mathrm{S} 4$ & 34.40 & 1.32 & 3.21 & 1.05 & 0.48 & 6.06 & 1.04 & 3.07 & 0.73 & 2.48 & 7.31 \\
\hline S5 & 9.18 & 2.38 & 1.53 & 0.18 & 0.50 & 4.59 & 0.81 & 2.68 & 0.28 & 0.97 & 4.75 \\
\hline S6 & 18.33 & 3.23 & 4.31 & 0.91 & 1.04 & 5.49 & 0.12 & 0.20 & $<0.09$ & $<0.12$ & 0.32 \\
\hline S7 & 11.02 & 1.77 & 5.93 & 0.21 & 0.54 & 8.45 & 8.03 & 2.62 & 0.69 & 1.92 & 13.26 \\
\hline S8 & 20.20 & 1.82 & 6.20 & 1.04 & 1.98 & 11.04 & 0.61 & 0.38 & 0.69 & $<0.12$ & 1.68 \\
\hline $\mathrm{S} 10$ & 13.82 & 3.53 & 3.32 & 1.69 & 1.11 & 9.65 & 1.78 & 3.91 & 0.38 & 1.28 & 7.35 \\
\hline \multicolumn{12}{|c|}{ July 12-13 (H2) } \\
\hline $\mathrm{S} 1$ & 8.20 & 2.29 & 1.40 & 0.72 & 0.97 & 5.38 & 59.24 & 11.04 & 0.72 & 4.43 & 75.43 \\
\hline $\mathrm{S} 2$ & 9.08 & 1.59 & 2.45 & 1.48 & 0.89 & 6.41 & 0.68 & 0.26 & $<0.09$ & 0.34 & 1.38 \\
\hline $\mathrm{S} 4$ & 12.40 & 1.41 & 1.56 & 1.68 & 0.68 & 5.33 & 2.53 & 7.35 & 2.29 & 5.47 & 17.64 \\
\hline S6 & 15.65 & 0.67 & 1.50 & 0.09 & 0.39 & 2.65 & 2.92 & 1.86 & $<0.09$ & $<0.12$ & 4.78 \\
\hline S8 & 10.54 & 1.06 & 7.00 & 1.79 & 1.74 & 11.59 & 1.35 & 1.60 & $<0.09$ & 0.70 & 3.65 \\
\hline S9 & 6.41 & 5.55 & 3.00 & 1.52 & 1.29 & 11.36 & $<0.04$ & 1.57 & $<0.09$ & $<0.12$ & 1.57 \\
\hline S10 & 4.15 & 2.77 & 1.10 & 0.41 & 0.48 & 4.76 & 0.44 & 4.54 & $<0.09$ & 0.82 & 5.80 \\
\hline S11 & 58.63 & 6.85 & 18.46 & 5.36 & 4.00 & 34.67 & 18.95 & 39.64 & 3.36 & 1.53 & 63.48 \\
\hline $\mathrm{S} 12$ & 33.00 & 55.82 & 19.46 & 10.99 & 38.27 & 124.54 & $<0.04$ & 0.67 & 0.74 & 5.03 & 6.43 \\
\hline $\mathrm{S} 13$ & 5.47 & 81.20 & 6.23 & 26.85 & 9.84 & 124.12 & 0.37 & 0.48 & 0.86 & 3.08 & 4.79 \\
\hline \multicolumn{12}{|c|}{ September 6-7 (H3) } \\
\hline $\mathrm{S} 1$ & 5.44 & 1.32 & 0.21 & $<0.05$ & $<0.04$ & 1.53 & 20.53 & 4.15 & 0.20 & 3.23 & 28.10 \\
\hline $\mathrm{S} 2$ & 6.52 & 0.67 & 1.00 & 0.07 & 0.22 & 1.96 & 1.35 & 0.54 & $<0.09$ & 0.80 & 2.69 \\
\hline $\mathrm{S} 3$ & 22.40 & 5.66 & 7.55 & 3.46 & 2.36 & 19.03 & 37.56 & 31.41 & 1.27 & 9.94 & 80.18 \\
\hline S4 & 7.30 & 3.34 & 1.13 & 0.96 & 1.10 & 6.53 & 5.14 & 2.57 & $<0.09$ & 0.89 & 8.61 \\
\hline S6 & 33.16 & 1.01 & 2.38 & 0.66 & 1.45 & 5.50 & 2.97 & 2.69 & $<0.09$ & $<0.12$ & 5.66 \\
\hline S8 & 8.54 & 1.07 & 7.07 & 1.52 & 2.06 & 11.72 & 2.05 & 1.00 & $<0.09$ & 1.30 & 4.36 \\
\hline S9 & 4.18 & 0.87 & 0.33 & 0.86 & 1.41 & 3.47 & 0.49 & 3.72 & 0.48 & 2.21 & 6.91 \\
\hline $\mathrm{S} 10$ & 4.66 & 0.90 & 0.40 & 0.74 & 0.63 & 2.67 & 1.14 & 6.45 & 0.87 & 3.44 & 11.89 \\
\hline S11 & 80.20 & 8.68 & 20.43 & 2.64 & 2.50 & 34.25 & 17.56 & 58.36 & 3.69 & 3.88 & 83.49 \\
\hline $\mathrm{S} 12$ & 45.66 & 51.47 & 20.72 & 13.47 & 16.72 & 102.38 & 9.26 & 7.18 & 0.92 & 3.25 & 20.61 \\
\hline $\mathrm{S} 13$ & 4.58 & 78.28 & 24.87 & 23.05 & 14.83 & 141.03 & 1.17 & 0.57 & 0.42 & 1.44 & 3.60 \\
\hline \multicolumn{12}{|c|}{ November $15-16$ (H4) } \\
\hline $\mathrm{S} 1$ & 37.02 & 2.30 & 1.44 & 0.23 & 0.33 & 5.30 & 25.19 & 4.03 & 0.59 & 2.72 & 32.54 \\
\hline $\mathrm{S} 2$ & 26.00 & 0.57 & 0.48 & 0.37 & 0.46 & 1.88 & 1.48 & 0.36 & 0.84 & 1.42 & 4.10 \\
\hline S3 & 53.50 & 4.88 & 7.95 & 3.87 & 2.06 & 18.76 & 31.70 & 18.01 & 0.97 & 11.03 & 61.71 \\
\hline $\mathrm{S} 4$ & 13.03 & 1.68 & 1.21 & 0.75 & 0.99 & 4.63 & 4.45 & 1.65 & 0.30 & 1.33 & 7.73 \\
\hline S6 & 44.69 & 1.79 & 2.60 & 0.75 & 0.51 & 5.65 & 4.25 & 2.85 & 0.31 & 0.54 & 7.85 \\
\hline S8 & 20.46 & 2.10 & 2.48 & 1.10 & 1.00 & 6.68 & 4.05 & 2.13 & 0.27 & 0.90 & 7.34 \\
\hline S9 & 8.42 & 1.44 & 0.84 & 1.35 & 1.08 & 4.71 & 0.58 & 3.14 & 0.31 & 1.26 & 5.29 \\
\hline $\mathrm{S} 10$ & 10.35 & 1.81 & 0.89 & 2.04 & 1.19 & 5.93 & 1.26 & 3.45 & 0.64 & 1.10 & 6.45 \\
\hline S11 & 19.07 & 7.71 & 20.65 & 2.64 & 2.24 & 33.24 & 12.36 & 48.35 & 2.36 & 5.62 & 68.69 \\
\hline $\mathrm{S} 12$ & 68.78 & 36.16 & 18.55 & 13.24 & 19.32 & 87.27 & 8.30 & 25.33 & 2.31 & 10.59 & 46.54 \\
\hline $\mathrm{S} 13$ & 10.01 & 61.67 & 13.79 & 15.70 & 17.03 & 108.19 & $<0.04$ & 1.48 & 3.83 & 16.72 & 22.03 \\
\hline
\end{tabular}

sediments and soils (Karickhoff, 1981). Our study shows that the concentrations of $\sum \mathrm{DDT}$, but not $\sum \mathrm{HCH}$, in sediments from Haihe River are correlated well with TOC contents $(r=0.553, p<0.05)$, which is possibly due to the less lipophilic and more volatile nature of $\mathrm{HCHs}$ relative to the DDTs. This relationship was also confirmed by Lee et al. (2001). The distributions of $\sum \mathrm{HCH}$ and $\sum \mathrm{DDT}$ in sediments along the Haihe River and Dagu Drainage River were shown in Figs. 2 and 3, respectively.

Fig. 2 shows that in general the concentrations of $\sum \mathrm{HCH}$ in sediments for samples S1 and S2 collected from Beiyun River and Ziya River and for samples S3-S10 from the Haihe River displayed uniform low distribution. Because, the sediment sample in the Nanyun River was not available, the contamination status of 
Table 2

Concentrations of $\sum \mathrm{HCH}$ and $\sum \mathrm{DDT}\left(\mathrm{ngg}^{-1} \mathrm{dw}\right)$ in surface sediments from large Chinese rivers and other world rivers, estuary and bays

\begin{tabular}{lllll}
\hline Locations & Sampling year & $\sum$ HCH & EDDT & References \\
\hline Haihe River & 2003 & $1.88-18.76(7.33)$ & $0.32-80.18(15.94)$ & This study \\
Daliaohe & 1989 & $0.50-0.80(0.65)$ & $0-0.40(0.20)$ & Wu et al. (1999) \\
Luanhe & 1991 & 0.20 & ND & Wu et al. (1999) \\
Changjiang & 1988 & $0.40-0.70(0.60)$ & $0.10-0.20(0.20)$ & Wu et al. (1999) \\
Huanghe & 1986 & $1.00-5.00(3.00)$ & ND & Wu et al. (1999) \\
Huangpujiang & 1988 & 2.90 & 1.30 & Wu et al. (1999) \\
Qiantangjiang & 1984 & 0.70 & 0.10 & Wu et al. (1999) \\
Jiulongjiang & 1993 & $0.29-0.69(0.49)$ & $4.10-6.10(5.20)$ & Zhang et al. (1996) \\
Minjiang & 1986 & $4.20-9.40(6.80)$ & $6.90-13.10(10.00)$ & Hu et al. (1996) \\
Pearl River & $1996-1997$ & $0.28-1.23(0.68)$ & $1.36-8.99(2.84)$ & Hong et al. (1999) \\
Wu-shi River, Taiwan & $1997-1998$ & $0.99-14.5(3.78)$ & $0.53-11.4(2.51)$ & Doong et al. (2002) \\
Osaka Bay, Japan & 1990 & 1.3 & 2.5 & Iwata et al. (1994) \\
Mandovi River Estuary, India & 1989 & 3.8 & 73 & Iwata et al. (1994) \\
Parramata River, Australia & 1990 & 7.7 & 26 & Iwata et al. (1994) \\
Swan River, Australia & 1990 & 1.2 & 750 & Iwata et al. (1994) \\
Mataniko River, Solomon Islands & 1990 & 140 & $<0.046-32$ & Iwata et al. (1994) \\
Kyeonggi Bay, Korea & 1995 & $<0.19-1.2$ & $<0.25-20$ & Lee et al. (2001) \\
Casco Bay, USA & 1991 & Lee et al. (2001) \\
\hline
\end{tabular}

$\mathrm{ND}$, not detected; A-B (C) means that the range of concentration is $\mathrm{A}-\mathrm{B} \mathrm{ngg}^{-1}$, while the mean value is $\mathrm{C} \mathrm{ngg}^{-1}$.

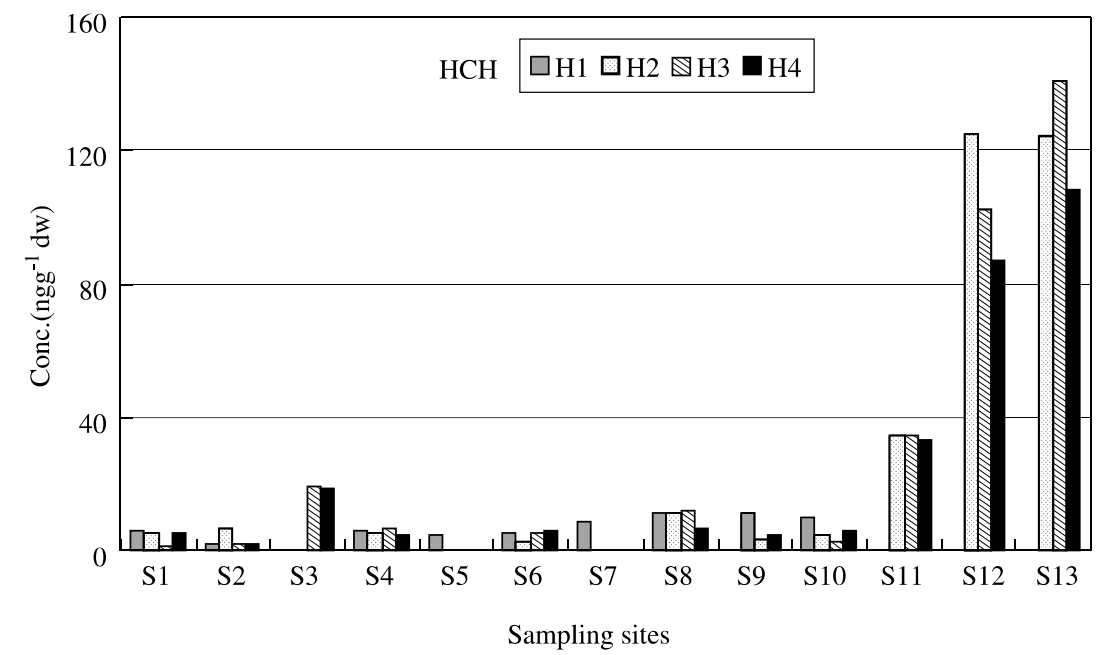

Fig. 2. The distributions of $\mathrm{\sum HCH}$ in sediments from the Haihe River and Dagu Drainage River.

the Nanyun River by $\mathrm{HCH}$ cannot be determined. However, after the three streams converged into the Haihe River in the urban area of Tianjin, a higher TOC content and $\mathrm{HCH}$ was found, indicating possibly relatively high historical input of $\mathrm{SHCH}$ from the Nanyun River. In addition, sediments from the Machangjian River showed the relatively higher content of $\sum \mathrm{HCH}$. In case of Dagu Drainage River, very high concentrations of $\sum \mathrm{HCH}$ were measured, especially in sediments of S12 and $\mathrm{S} 13$, indicating important sources of $\mathrm{HCH}$ in this re- gion. In fact, there were many chemical manufactures, including $\mathrm{HCH}$ and DDT producers, operated near the sites of $\mathrm{S} 12$ and $\mathrm{S} 13$.

A different distribution pattern has been found for DDT. Obviously, Beiyun River was seriously contaminated by DDT compounds, while Ziya River was much less polluted. Similarly, although the pollution of DDT in Nanyun River was unclear, the Beiyun River is probably one of the major contributors of DDT in the urban sites of Haihe River due to the high concentration of 


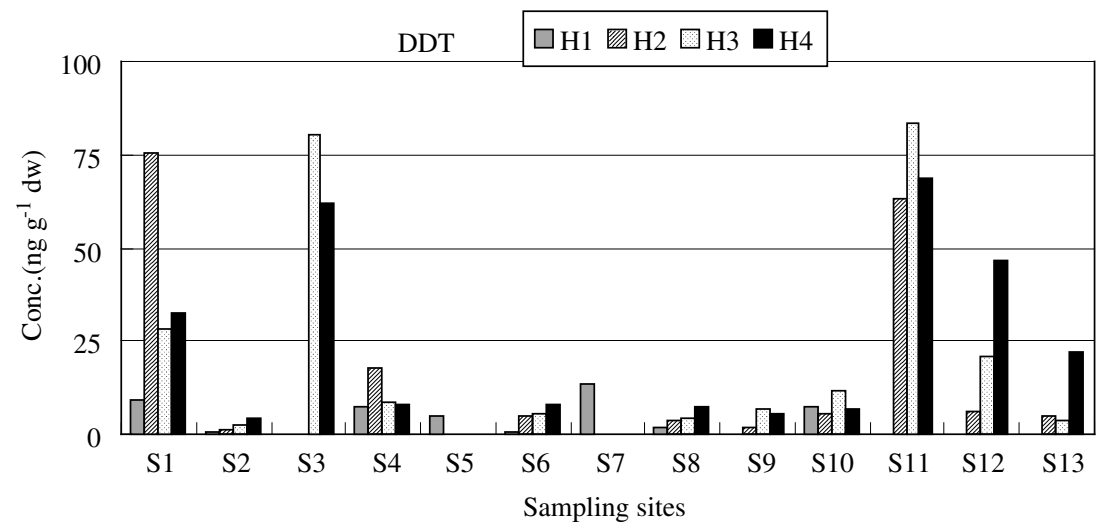

Fig. 3. The distributions of $\sum D D T$ in sediments from the Haihe River and Dagu Drainage River.

$\sum D D T$ in the samples from the converged site (S3). In the other samples from the Haihe River showed the medium contamination level of $\sum D D T$. The Dagu Drainage River also showed the high level of $\sum$ DDT.

\subsection{Compositions analyses}

Composition differences of $\mathrm{HCH}$ isomers or DDT congeners in the environment could indicate different contamination sources (Iwata et al., 1995; Doong et al., 2002). Technical HCH has been used as a broad spectrum pesticide for agricultural purpose, which has been officially banned since 1983 in China. The typical technical $\mathrm{HCH}$ generally contains $55-80 \%$ of $\alpha-\mathrm{HCH}$, $5-14 \%$ of $\beta-\mathrm{HCH}, 8-15 \%$ of $\gamma-\mathrm{HCH}$ and $2-16 \%$ of $\delta$-HCH, respectively (Lee et al., 2001). The physicochemical properties of these $\mathrm{HCH}$ isomers are different. $\beta$-HCH has the lowest water solubility and vapor pressure, which is the most stable and relatively resistant to microbial degradation (Ramesh et al., 1991). Also it should be noted that $\alpha-\mathrm{HCH}$ can be converted to $\beta$ -
$\mathrm{HCH}$ in the environment (Wu et al., 1997; Walker, 1999). Therefore, the predominant of $\alpha$-isomer in some environmental samples reflects the recent use of technical HCH (Kannan et al., 1995). Many studies have reported that $\beta-\mathrm{HCH}$ was dominant in sediments from the river or estuary environment after long-term migration and transformation (Wu et al., 1999; Lee et al., 2001; Doong et al., 2002). However, regarding the composition of $\mathrm{HCH}$ isomers measured in this study, a high percentage of $\alpha$ isomers was recorded (Fig. 4). The average compositions of $\mathrm{HCH}$ isomers measured in the samples are $\alpha: 59.0 \%, \beta: 32.7 \%, \gamma: 5.7 \%$ and $\delta: 2.5 \%$.

Technical DDT generally contains $75 \% p, p^{\prime}$-DDT, $15 \% o, p^{\prime}$-DDT, $5 \% p, p^{\prime}$-DDE, and $<5 \%$ others. DDT can be biodegraded to DDE under aerobic condition and to DDD under anaerobic condition (Kalantzi et al., 2001). Comparing the concentrations of $p, p^{\prime}$ DDT and its metabolites, it can be inferred whether DDT's input are recent or not (Phuong et al., 1998). The ratio of $(\mathrm{DDE}+\mathrm{DDD}) / \sum \mathrm{DDT}>0.5$ can be thought to be subjected to a long-term weathering (Hites

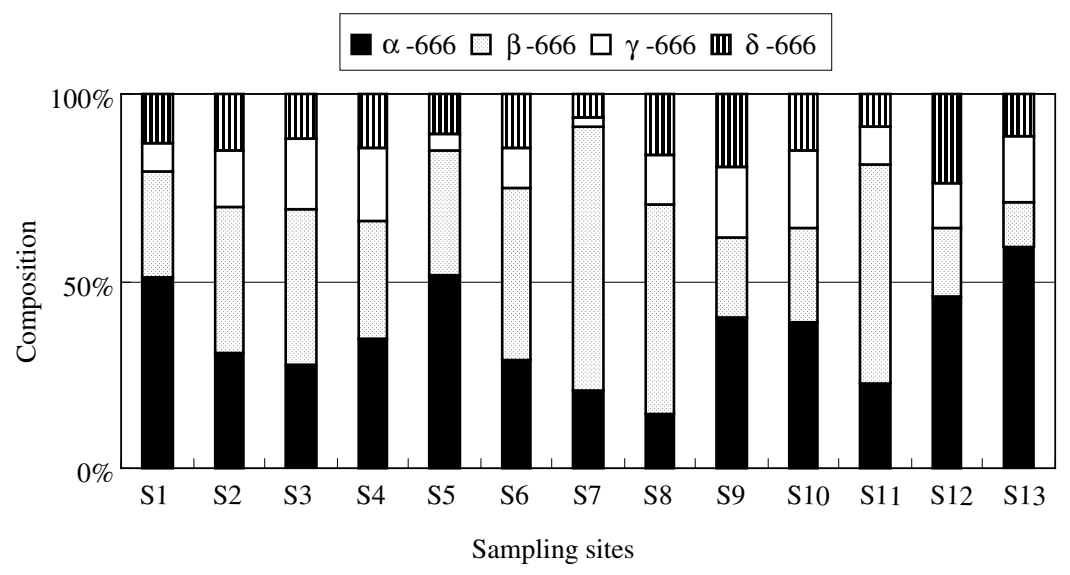

Fig. 4. Composition of HCHs in sediments from the Haihe River and Dagu Drainage River. 


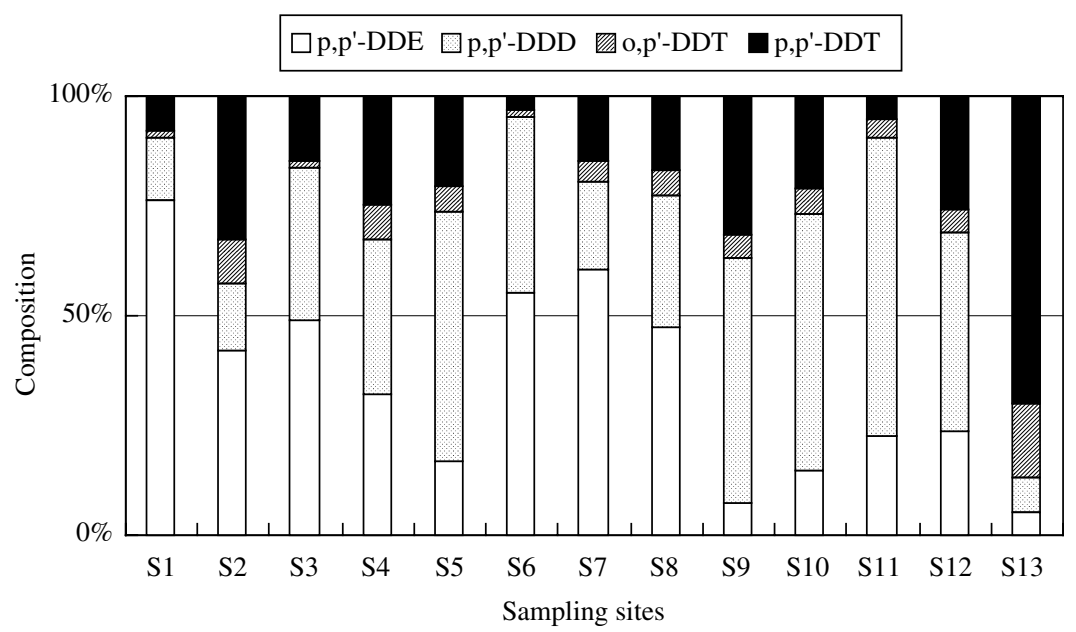

Fig. 5. Composition of DDTs in sediments from the Haihe River and Dagu Drainage River.

and Day, 1992; Hong et al., 1999). In most present samples, DDE and DDD occupied the predominant percentage (Fig. 5). Here the mean ratio of (DDE + DDD)/ $\sum \mathrm{DDT}$ in the sediments from the Haihe River was 0.76 , which indicated that the degradation occurred significantly. For the Dagu Drainage River, in sediment of $\mathrm{S} 11$ and S12, the breakdown products of DDE and DDD occupied predominant percent of DDTs. However, the $p, p^{\prime}$-DDT in the sediment of S13 occupied about $70 \%$. The high levels of $\sum D D T$ and high percentage of DDT indicated the recent input of DDT into the downstream of the Dagu Drainage River.

\section{Conclusion}

This work investigated the contamination status of $\mathrm{HCH}$ and DDT in surface sediments of the Haihe River and Dagu Drainage River. Wide occurrence and high residue levels of these two OCPs have been found in the study areas, especially for the Dagu Drainage River. The distribution of $\sum \mathrm{DDT}$ and $\mathrm{\sum HCH}$ was different, indicating their different contamination sources. The Ziya River, one of the main branches of the Haihe River, was seriously contaminated by DDT. Composition analyses and high residue levels of $\mathrm{HCH}$ and DDT indicated that a recent input of these two OCPs into the Dagu Drainage River.

\section{Acknowledgement}

The authors would like to thank the National Basic Research Program of China (2003CB415001) and the Chinese Academy of Sciences (KZCX2-414) for the financial supports.

\section{References}

Doong, R.A., Peng, C.K., Sun, Y.C., Liao, P.L., 2002. Composition and distribution of organochlorine pesticide residues in surface sediments from the Wu-Shi River estuary, Taiwan. Mar. Pollut. Bull. 45, 246-253.

Gong, Z.M., Xu, F.L., Dawson, R., Cao, J., Liu, W.X., Li, B.G., Shen, W.R., Zhang, W.G., Qin, B.P., Sun, R., Tao, S., 2004. Residues of hexachlorocyclohexane isomers and their distribution characteristics in soils in the Tianjin area, China. Arch. Environ. Contam. Toxicol. 46, 432437.

Hites, R.K., Day, H.R., 1992. Unusual persistent of DDT in some western USA soils. Bull. Environ. Contam. Toxicol. 48, 259-264.

Hong, H., Chen, W., Xu, L., Wang, X., Zhang, L., 1999. Distribution and fate of organochlorine pollutants in the Pearl River Estuary. Mar. Pollut. Bull. 39, 376-382.

Hu, M.H., Yang, Y.P., Xu, X.H., 1996. Estuarine geochemistry of the Minjiang River. In: Zhang, J. (Ed.), The Biogeochemistry of Major Chinese Estuaries. Oceanic Press, Beijing, pp. 241-242 (in Chinese).

Iwata, H., Tanabe, S., Sakai, N., Nishimura, A., Tatsukawa, R., 1994. Geographical distribution of persistent organochlorine in air, water, and sediments from Asia and Oceania and their implications for global redistribution from lower latitudes. Environ. Pollut. 85, 15-33.

Iwata, H., Tanabe, S., Ueda, K., Tatsukawa, R., 1995. Persistent organochlorine residues in air, water, sediments, and soils from the lake Baikal region, Russia. Environ. Sci. Technol. 29, 792-801.

Kalantzi, Q.I., Alcock, R.E., Joneston, P.A., Santillo, D., Stringer, R.L., Thomas, G.O., Jones, K.C., 2001. The global distribution of $\mathrm{PCBs}$ and organochlorine pesticides in butter. Environ. Sci. Technol. 35, 1013-1018.

Kannan, K., Tanabe, S., Tatsukawa, R., 1995. Geographical distribution and accumulation features of organochlorine residues in fish in tropical Asian and oceania. Environ. Sci. Technol. 29, 2673-2683. 
Karickhoff, S.W., 1981. Semi-empirical estimation of sorption of hydrophobic pollutants on natural sediments and soils. Chemosphere 10, 833-846.

Lee, K.T., Tanabe, S., Koh, C.H., 2001. Distribution of organochlorine pesticides in sediments from Kyeonggi bay and nearby areas, Korea. Environ. Pollut. 114, 207-213.

Phuong, P.K., Son, C.P.N., Sauvain, J.J., Tarradellas, J., 1998. Contamination by PCB's, DDT's and heavy metals in sediments of Ho Chi Minh City's canals, Vietnam. Bull. Environ. Contam. Toxicol. 60, 347-354.

Ramesh, A., Tanabe, S., Murase, H., Subramanian, A.N., Tatsukawa, R., 1991. Distribution and behavior of persistent organochlorine insecticides in paddy soil and sediments in the tropical environment: a case study in South India. Environ. Pollut. 74, 293-307.

Walker, K., 1999. Factors influencing the distribution of lindane and other hexachlorocyclohexanes in the environment. Environ. Sci. Technol. 33, 4373-4378.

Willett, K.L., Ulrich, E.M., Hites, S.A., 1998. Differential toxity and environmental fates of hexachlorocyclohexane isomers. Environ. Sci. Technol. 32, 2197-2207.
Wu, W., Xu, Y., Schramm, K.W., Kettrup, A., 1997. Study of sorption, biodegradation and isomerization of $\mathrm{HCH}$ in simulated sediments/water system. Chemosphere 35, 18871894.

Wu, Y., Zhang, J., Zhou, Q., 1999. Persistent organochlorine residues in sediments from Chinese river/estuary systems. Environ. Pollut. 105, 143-150.

Yang, R.Q., Yao, Z.W., Jiang, G.B., Zhou, Q.F., Jiu, J.Y., 2004. HCH and DDT residues in molluses from Chinese Bohai coastal sites. Mar. Pollut. Bull. 48, 785-799.

Zhang, L.P., Chen, W., Lin, L.M., Hong, H.S., 1996. Concentrations and distribution of $\mathrm{HCHs}$, DDTs, and $\mathrm{PCBs}$ in surface sediments of Xiamen Western Bay. Tropic Oceanol. 15 (1), 91-95.

Zhou, J.L., Maskaoui, K., Qiu, Y.W., Hong, H.S., Wang, Z.D., 2001. Polychlorinated biphenyl congeners and organochlorine insecticides in the water column and sediments of Daya Bay, China. Environ. Pollut. 113, 373-384. 